\title{
Design of analog field programmable cmos current conveyor
}

\author{
G. Kapur ${ }^{1}$, S. Mittal ${ }^{2}$, C. M. Markan ${ }^{1}$, V. P. Pyara ${ }^{1}$ \\ ${ }^{1}$ Dayalbagh Educational Institute, Dayalbagh, Agra, India \\ ${ }^{2}$ Indian Institute of Kanpur, Kanpur, India
}

Email address:

kapur.garima@gmail.com (G. Kapur), sajalmitta182@yahoo.co.in (S. Mittal), cm.markan@gmail.com (C. M. Markan), vpprempyara@gmail.com(V. P. Pyara)

\section{To cite this article:}

G. Kapur, S. Mittal, C. M. Markan, V. P. Pyara. Design of Analog Field Programmable CMOS Current Conveyor, Science Journal of Circuits, Systems and Signal Processing. Vol. 1, No. 1, 2012, pp. 9-21. doi: 10.11648/j.cssp.20120101.12

\begin{abstract}
The paper propose a modified high frequency current controlled current conveyor CMOS circuit CCCII where current gain, current controlling intrinsic impedance and circuit offsets are programmable independently to desired values within a specific field range after fabrication with the help of field programmable floating gate transistors FGMOS. The programmable charge at floating-gate of FGMOS using external voltages results in its threshold voltage variation, which in turn program the design (CCCII) specifications. The circuit occupies low power, about $1.509 \mathrm{~mW}$ total power dissipation and shows higher temperature stability $\left(0.0287 \mathrm{uA} /{ }^{\circ} \mathrm{C}\right.$ variation in output current with temperature change). With specific sizing and biasing condition, the current gain can be programmed from 0.2 to 2.1 , intrinsic impedance from $15 \mathrm{~K}$ to $51 \mathrm{~K}$, while offset current can be compensated, independently using each FGMOSFETs, respectively, with 13-bit precision. However the final programmable CCCII circuit with FGMOSFETs occupies $65 \mu \mathrm{m} \times 54 \mu \mathrm{m}$ chip area. The circuit finds application in systems where field-programmability of the design using smaller sized hardware is required like universal filter, current control high frequency oscillator, etc as compared to the circuits using current control conveyor based FPAAs.
\end{abstract}

Keywords: Current Controlled Conveyor, Floating-Gates, Field Programmable Specifications, Field Programmable Threshold Voltage

\section{Introduction}

With CMOS scaling down, to maintain integration suitability current mode devices are finding more consideration in circuit designs. As supply voltage has become the great concern in present electronic design scenario especially for portable, battery powered equipment. Thus current-mode circuits like current conveyors are better suited for such purpose in comparison with voltage-mode ones. Current conveyor is a versatile analog circuit building block that offers an alternative method of implementing analog systems which traditionally have been based on voltage op-amps. It is a three terminal analog device which acts as an amplifier with unity gain without any overall negative feedback (between output $\mathrm{Z}$ and input $\mathrm{X}$ of figure 1 (a)), rather than the ill-defined open-loop gain and closed loop gain-bandwidth conflict of negative feedback voltage op-amp [1]. Thus the CC based amplifier does not depend critically on the matching of external components, instead depends only on the absolute value of a single component. It can provide a higher gain over a larger signal bandwidth under small or large signal conditioning than corresponding op-amp circuits [2]. Although the CC concept has been around for a long time with the first generation $\mathrm{CC}$ (CCI) proposed in 1968 and the more versatile and adaptable second generation CCII in 1970 [3, 4]. In CCI both the currents and the voltages in ports $\mathrm{X}$ and $\mathrm{Y}$ are forced to be equal and a replica of the currents is mirrored (or conveyed) to the output port $\mathrm{Z}$. Whereas in CCII input $\mathrm{Y}$ draws no current and Figure 1 (b) also depict its voltage-current describing matrix. With higher accuracy, bandwidth and because of the combined voltage and current properties in CCII circuit, it may be used to synthesize a number of analog circuit functions which are not so easily or accurately realizable using op-amp [5, 6]. However a major shortcoming of CCII is that it cannot control the parasitic resistance at X $\left(R_{x}\right)$ thus, when it is used in some circuits, it must unavoidable require some external passive components, especially resistors. This makes it not appropriate for IC implementation due to occupying more chip area, high power dissipation and no electronic controllability. Thus second generation current controlled current conveyor CCCII have 
been introduced which provide electronic adjustability (illustrated via voltage-current matrix of CCCII circuit in Figure 1(c)) over CCII [7-11]. It allows implementation of electronic functions, usable at high frequency. Moreover, the current controllable resistance $\mathrm{R}_{\mathrm{x}}$ is usable for the applications of tunable circuits. Therefore, this conveyor becomes useful in high frequency applications filtering [12] and, oscillator [13].

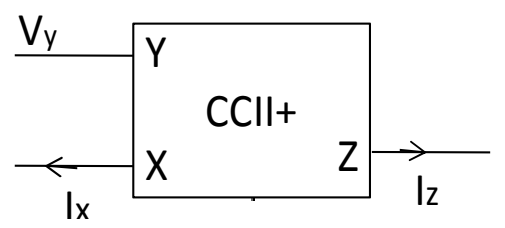

(a)

$$
\left[\begin{array}{c}
I_{y} \\
V_{x} \\
I_{z}
\end{array}\right]=\left[\begin{array}{c}
000 \\
100 \\
0 \pm 1
\end{array}\right]\left[\begin{array}{l}
V_{y} \\
I_{x} \\
V_{z}
\end{array}\right]
$$

(b)

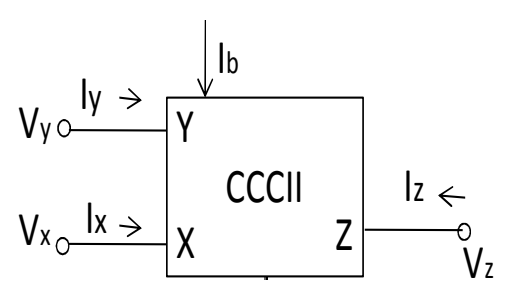

(c)

$$
\left[\begin{array}{l}
I_{y} \\
V_{x} \\
I_{z}
\end{array}\right]=\left[\begin{array}{ccc}
0 & 0 & 0 \\
1 & R_{x} & 0 \\
0 & \pm & 10
\end{array}\right]\left[\begin{array}{l}
V_{y} \\
I_{x} \\
V_{z}
\end{array}\right]
$$

(d)

Figure 1. (a) shows schematic of CCII. (b) CCII, I-V describing matrix. The voltage at the low impedance input $X$ follows that at the high impedance input $Y$, while the input current node $X$ is mirrored or 'conveyor' to the high-impedance output node $Z$. The +- sign indicates the polarity of the output current w.r.t the input current. (c) Schematic of CCCII (d) CCCII, I-V Matrix. The $I_{b}$ is biasing current, by which the voltage relation between terminal $X$ and terminal $Y$ is adjusted. Rx shows parasitic resistor of terminal $X$ and it is a function of $I_{b}$. The parasitic resistance Rx of terminal $X$ is proportional to $1 / I_{b}$.

Now, as analog devices/circuits lack in accurate prototyping of the design, reconfiguring ability and automation, programmable devices like Field Programmable Analog Array (FPAA) have been developed. A FPAA is an integrated circuit, which can be configured to implement various analog functions using a set of configurable analog blocks $(\mathrm{CAB})$ and a programmable interconnection network, and is programmed using on-chip memories [14]. The CAB can be implemented using different analog active circuits like a tunable unity gain frequency op-amp[14], programmable operational transconductance amplifier(OTA)[15], or programmable current conveyor [16]. The design challenges of the FPAA are mainly the CAB active circuit and the interconnection network. If the active circuit is programmable, then the FPAA user can implement tunable analog circuit applications such as on-chip tunable filters and variable gain amplifiers. Due to design complexity of op-amp based programmable active circuits they are not the efficient for most of the FPAA design. However tunable OTA using pre-defined set of control voltage signals, based FPAA design requires extra hardware to save the control voltage values [17]. In addition, digitally programmable fully differential second generation current conveyors (DPCCII) are also used in FPAA with an advantage of no additional circuitry for interconnections [18]. Various techniques are used to program CCII, first one was using a current division network (CDN) added in cascade with current follower [19]. The CDNs require current sources for biasing and maintaining circuit transistors in saturation region, thus increases circuit power consumption. Second approach was using current mirror to scale the current at $\mathrm{Z}$ port, however, this method can subject to transistors mismatching problems [20]. Third approach was using 3bit MOS R-2R ladder current division network, in which current scaling factor changes with 3-bit digital codeword applied to CDN [18]. Furthermore, various current mode reconfigurable analog modules were also proposed using low voltage digitally programmed current conveyor (DPCCII), where 4-bit control word is considered [20]. These digitally control designs had improved the on chip control of continuous time systems with reconfigurability but these designs experience limitation in applications where low power consumption, small size hardware, high resolution and continuous/analog programming instead of digital switching are required, like in highly integrated portable electronic devices. There are various electronic systems where high precision tuning ability/programmability is required like for biologically inspired circuits such as bionic ear processor, learning circuits and related adaptive filters, neuromorphic and cellular computing circuits, etc. However as illustrated earlier, CCCII has an advantage of tuning ability over CCII, whereas on-chip programming ability with the help of bias current will bring changes in the circuit operating conditions or rather result in circuit offsets. Programmable CCCII based FPAA can bring paradigm shift in programming and implementing electronics for above mentioned areas.

Thus to introduce continuous programming ability in CCCII design, we propose a comprehensive design procedure which allows post fabrication and independent tuning of critical specifications to desired values within a specific field range using analog voltages. In our proposed design flow instead of repeatedly iterative simulation steps to achieve very precise design specifications by fine tuning the $\mathrm{W} / \mathrm{L}$ ratios of the FETs, we use first order classroom equations to achieve central value of desired specifications and then execute a customized fine tuning of specifications to the customers requirement. While maintaining small size and low power consumption FGMOS are introduced in place of conventional MOS device with which conductivity of a MOS can be corrected by altering its threshold voltage $\left(\mathrm{V}_{\mathrm{T}}\right)$ by a field user $[21,22]$. The CCCII circuit is analyzed 
and derived in terms of design specifications whose derived equations show direct dependence on MOS thresholds. FGMOS offers continuous variation in threshold by storing the weights in a non-volatile analog memory with high accuracy [23, 24, and 25]. And the charge once stored at FG can be retained for more than 10 years. Thus a FPAA based on our proposed analog programmable CCCII design will not required extra hardware for storing, no digital code controlling circuitry however it will require interconnects to provide desired analog voltages to program floating gates of respective FGMOSs. In paper, parametric analysis of each design specification with respect to each FGMOS is performed and circuit is modified to achieve independent programming ability of design specification as well as circuit offsets, using respective FGMOSs. The total power dissipation and thermal stability of the modified design is also being catered in the paper. Such consistent approach to introduce programmability can be applied to various analog ICs (the idea of programmability using floating gate transistor is being published in conferences before [26, 27 and 28]).

\section{Design Objectives}

Before designing or introducing programmability in CCCII CMOS circuit, few design objectives need to be considered. Firstly the variation in the design specifications should be large and continuous. Indirect, non-volatile and high precision programming of FGMOS thresholds can produce large range and continuous programming of specifications. However, large continuous variation in specifications is difficult and sometimes unstable. Second design objective is that the variation of each specification should be independent of the other i.e., each specification should be programmed either by one or more FGMOS but should not alter any other design specifications. However if specification programming are not independent then either through modifying the circuit or by compensating the affected specification value using different set of FGMOS, should be prepared. Thirdly, operating point of the circuit should not alter too much during programming, i.e. current density in each transistor should not change significantly or in other words offset current should not vary significantly.

\section{Basic CCCII Circuit Design}

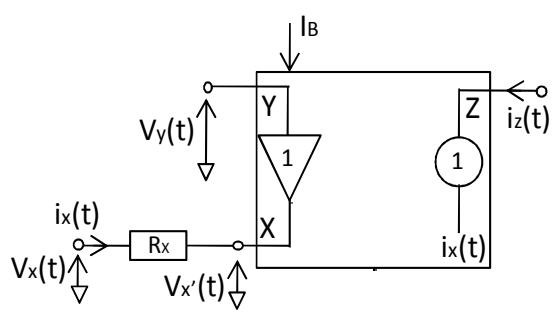

(a)

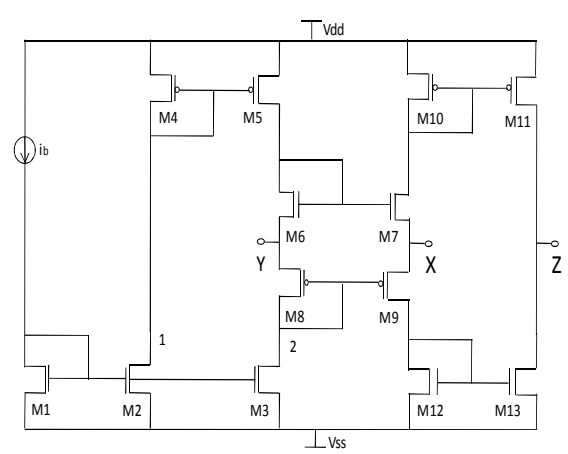

(b)

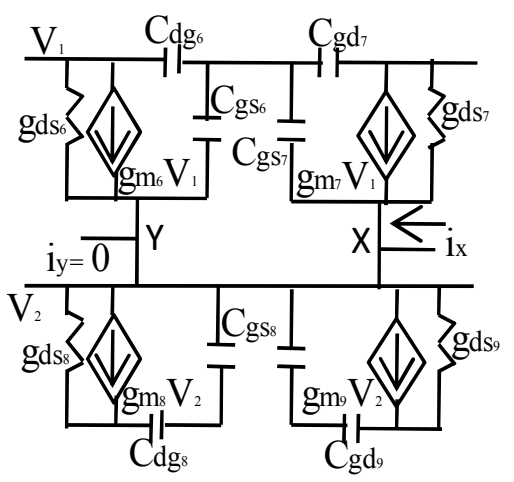

(c)

Figure 2. (a): Equivalent circuit of an ideal CCCII [5] (b): Circuit diagram of CMOS CCCII [5] (c) High frequency small signal equivalent circuit of mixed Translinear loop of the CCCII circuit.

The CMOS CCCII design [13] consists of four symmetric current mirrors and a mixed Translinear loop with one low impedance input (controlled by bias current), one high impedance input, one high impedance output, a suitable element for both voltage-mode and current-mode circuits. It basically consists of four current mirrors and a mixed Translinear loop. Equivalent circuit of an ideal CCCII is shown in Figure 2(a). It gives a high impedance input at port $\mathrm{Y}$ and a low impedance input at port $\mathrm{X}$. With low magnitude input current $i_{x}(t)$, the mixed Translinear loop force the drain current of its each transistor equal to $\mathrm{I}_{\mathrm{b}}$. Consequently, it gives $V_{x}(t)=V_{y}(t)$, (voltage follower represented in Figure 2(a)). Hence, the equivalent voltage follower presents at port $\mathrm{X}$ a small signal intrinsic resistor $\mathrm{R}_{\mathrm{x}}$ that is inversely proportional to the square root of the bias current $\mathrm{I}_{\mathrm{b}}$ (as derived from high frequency small signal equivalent model and expressed in equation (1) and (2) in next section). The two complementary current mirrors allow to duplicate on port $\mathrm{Z}$ the input current at $X$, thus $i_{Z}(t)=i_{X}(t)$ (Current follower action between $X$ and $Z$ ). Figure 2(b) shows the circuit diagram of CMOS CCCII referred from paper [5] and Figure 2(c) represents high frequency small signal equivalent circuit of mixed Translinear loop of the CCCII circuit.

\subsection{High Frequency Small Signal Analysis}

The CCCII design is operated at high frequency; accor- 
dingly high frequency small signal equivalent model is generated and design characteristics are derived. The bias current $I_{b}$ is mirrored equally to two nodes of the mixed Translinear loop, node $1 \&$ node 2, as shown in Figure 2(b). NFET and PFET current mirrors are replaced by their respective small signal model in the Translinear loop as shown in Figure 2(c). The input current from port $\mathrm{X}$ is then mirrored using PFET and NFET current mirrors (M10, M11 and M12, M13), to the output port Z. From the small signal equivalent circuit of the design, current gain $\left(i_{z}(t) / i_{x}(t)\right)$, voltage gain $\left(V_{x} / V_{y}\right)$, intrinsic resistance $R_{x}$, output impedance $R_{\text {out }}$ and dc offsets at $\mathrm{X}$ and $\mathrm{Z}$ has been derived and derived expression are as follows. Resistance $R_{x}$, using Thevenin theorem at port $\mathrm{X}$, is given by:

$$
R_{X}=\frac{1}{g_{m 7}+g_{m 9}}
$$

where, transconductance gm $7 \&$ gm6, can be expressed in terms of square root of their respective saturation drain currents,

$$
g_{m}=\frac{k_{n}^{\prime} W / L}{2}\left(\sqrt{\frac{I_{b}}{k_{n}^{\prime} / 2 W / L}}\right.
$$

Thus, $\mathrm{Rx}$ is inversely proportional to the square root of the bias current $\mathrm{Ib}$. The voltage gain $(\mathrm{Vx} / \mathrm{Vy})$ across port $\mathrm{X}$ and $\mathrm{Y}$ in the design is expressed as:

$$
A_{v}=\frac{\left(s\left(C_{g s 6}+C_{g s 7}\right)+g_{m 6}+g_{m 7}\right)\left(s C_{g d 2}-g_{m 2}\right)\left(s C_{g d 5}+g_{m 5}\right)}{\left(g_{m 7}+s C_{g s 7}\right)\left(s C_{g d 2}+g_{d s 2}\right)\left(s C_{g d 5}+g_{d s 5}\right)} \frac{V_{b}}{V_{Y}}-\frac{\left(g_{m 6}+s C_{g s 6}\right)}{\left(s C_{g s 7}+g_{m 7}\right)}
$$

where, $\mathrm{Vb}$ is the voltage across the bias current $\mathrm{Ib}$ of the circuit. Moreover, current gain $\mathrm{Ai}=\mathrm{iz}(\mathrm{t}) / \mathrm{ix}(\mathrm{t})$, assuming id6 $=\mathrm{id} 7=\mathrm{id} 8$ and $\mathrm{id} 9=\mathrm{id} 7+\mathrm{ix}$, is expressed as:

$$
\begin{gathered}
A_{i}=\frac{\left(s C_{g d 5}+g_{m 5}\right)\left(s C_{g d 2}-g_{m 2}\right)}{\left(s\left(C_{g d 5}+C_{g s 5}+C_{g s 4}\right)-g_{m 4}\right)\left(s\left(C_{g s 1}+C_{g s 2}+C_{g d 2}\right)+g_{m 1}\right)} \frac{I_{b}}{i_{x}} \\
{\left[\frac{s C_{g d 11}+g_{m 11}}{\left(s\left(C_{g d 11}+C_{g s 10}+C_{g 11}\right)-g_{m 10}\right.}-\frac{s C_{g d 13}-g_{m 13}\left(C_{g s 12}+C_{g s 13}+C_{g d 13}\right)+g_{m 12}}{\left(\frac{s C}{s\left(C_{g d 13}+C_{g s 13}+C_{g s 12}\right)+g_{m 12}}\right.}\right]-}
\end{gathered}
$$

Output impedance at port $\mathrm{Z}$ from small signal equivalent circuit of the CCCII design is being derived as:

$$
R_{\text {out }}=\frac{1}{\left(g_{d s 2}+g_{d s 3}+g_{d s 5}+g_{d s 7}+g_{d s 9}+g_{d s 11}+g_{d s 13}\right)+}
$$

The graphs representing $\mathrm{Rx}$ variation with bias current $\mathrm{Ib}$ and frequency response of current gain and voltage gain are shown in Figure 3(d). Moreover, DC offset voltage at X and offset current at $\mathrm{Z}$ can be expressed by neglecting all parasitic capacitances in the expression (3) and (4) with no input voltage Vy or input current $\mathrm{ix}(\mathrm{t})$, respectively. Hence the output offset voltage at $\mathrm{X}$ is given by:

$$
V_{\text {offset }} \cong-g_{m 2} g_{m 5}\left(g_{m 6}+g_{m 7}\right) V_{b}
$$

and output offset current at $\mathrm{Z}$ is given by:

$$
I_{\text {offset }} \cong \frac{g_{m 5} g_{m 2}}{g_{m 1} g_{m 4}}\left[\frac{g_{m 13}}{g_{m 12}}-\frac{g_{m 11}}{g_{m 10}}\right] I_{b}
$$

\subsection{Characteristics of Basic CCCII Design}

The proposed programmable modified CCCII design is simulated and its basic functionality with central value of specifications at specific biasing and sizing conditions of the circuit is estimated. The design characteristic plots like frequency response of current gain and voltage gain is represented in Figure 3(a) and (b). Figure 3(c) shows the input current $i_{x}(800 \mathrm{MHz}$ frequency and 10uA amplitude sine wave) and the output current $i_{z}$. The graph in Figure $3(d)$ proves that the resistance $R_{x}$ is inversely proportional to $I_{b}$. It shows theoretical and simulated values are in good agreement. The intrinsic resistance $\mathrm{R}_{\mathrm{x}}$ varies from $21.194 \mathrm{k} \Omega$ to $21.338 \mathrm{k} \Omega$ when $\mathrm{I}_{\mathrm{b}}$ is varied from $1.5 \mathrm{~mA}$ to $0.5 \mathrm{~mA}$. Figure 3(e) demonstrates the variation in output current with change in temperature from $-40^{\circ} \mathrm{C}$ to $80^{\circ} \mathrm{C}$.

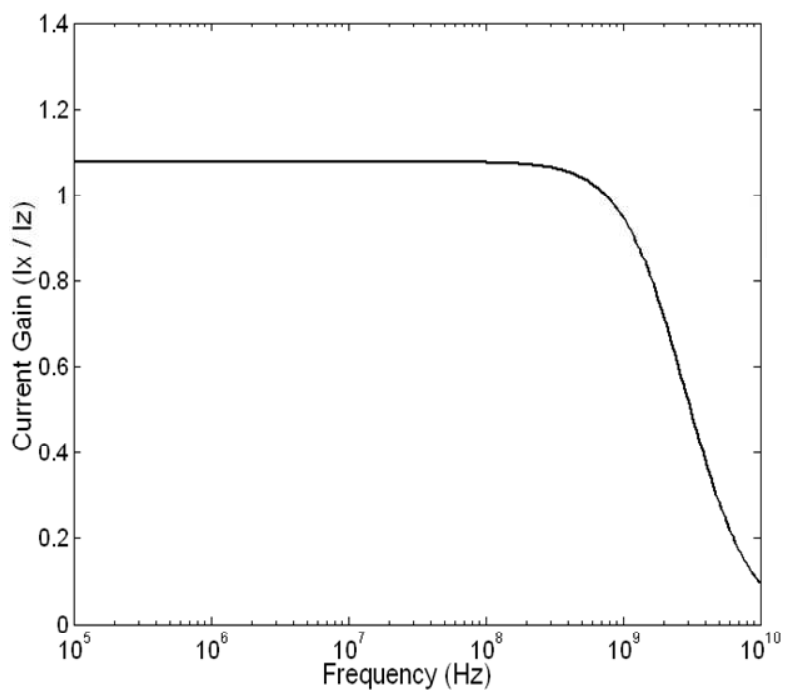

(a)

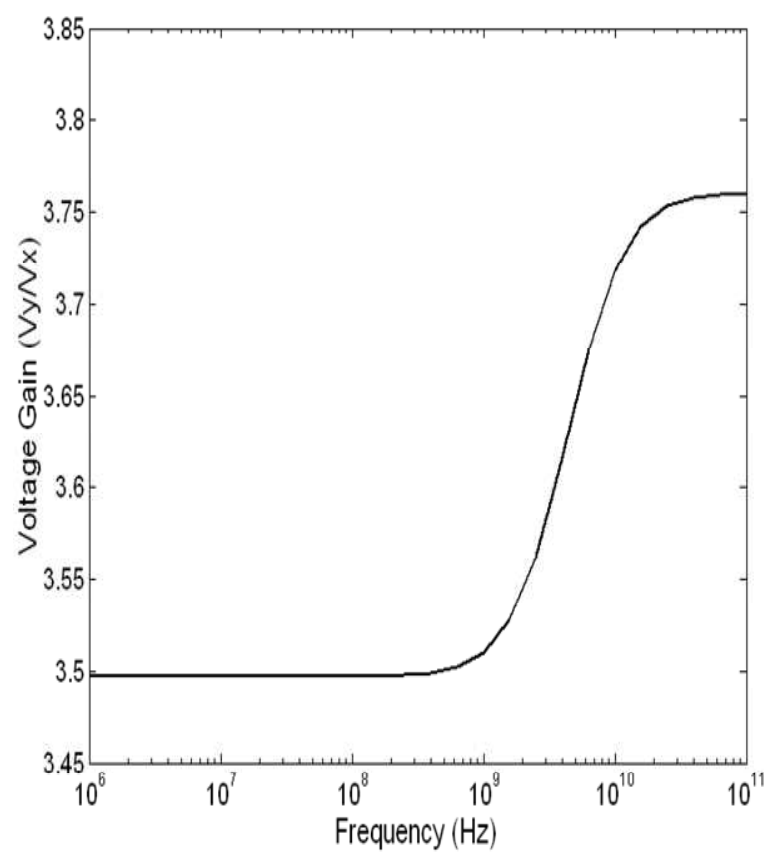

(b) 


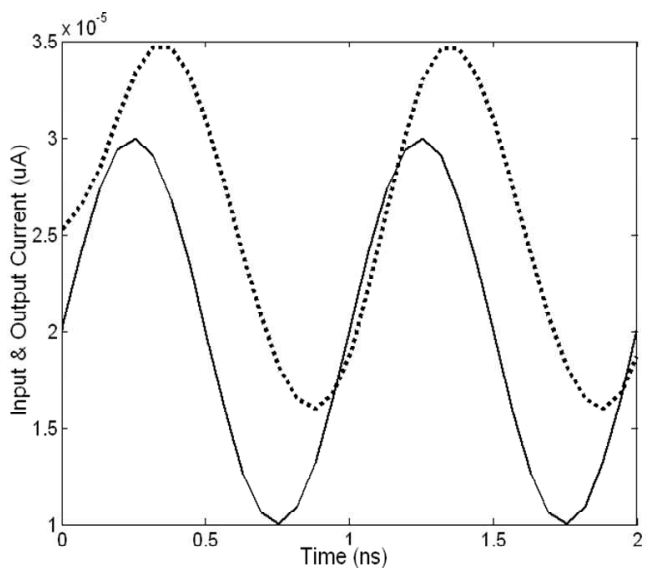

(c)

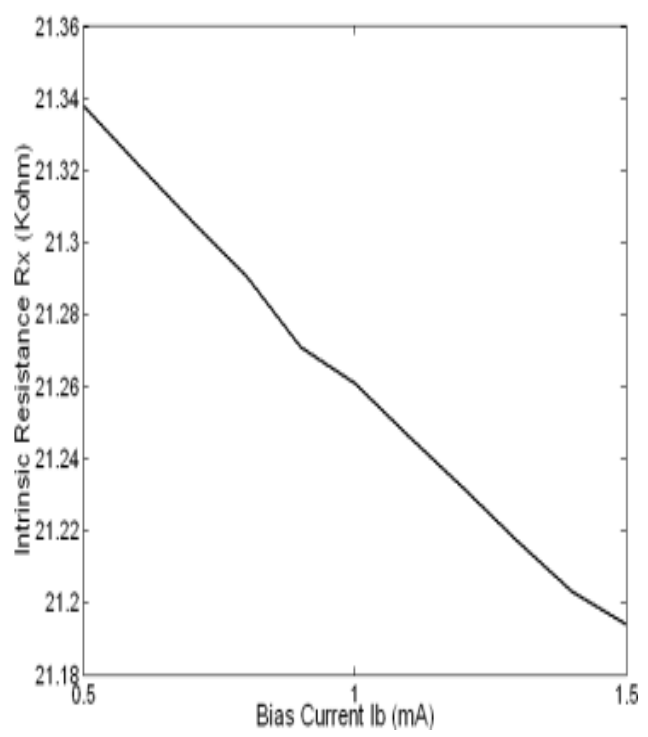

(d)

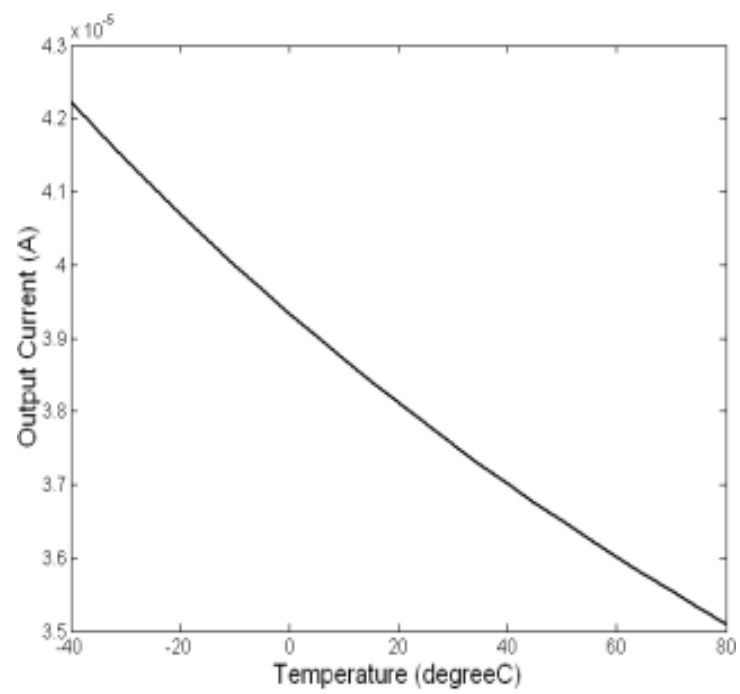

(e)

Figure 3. Frequency Response of (a) Current Gain (Iz/Ix) (b) Voltage Gain $\left(V_{x} / V_{y}\right)(c)$ Input signal (10u \& \& 800meg) and corresponding output signal (dotted curve) (d) Intrinsic resistance variation on varying bias current from $0.5 \mathrm{~mA}$ to $1.5 \mathrm{~mA}$ (e) Variation in output current with change in temperature from $-40^{\circ} \mathrm{C}$ to $80^{\circ} \mathrm{C}$. (about $0.0287 u A /{ }^{\circ} \mathrm{C}$ temperature stability).

\section{Design of Programmable CCCII}

\subsection{Programming Technique}

To introduce programmability in basic CCCII circuit, all MOSFETs are replaced by FGMOSs. Floating-gate MOS is conventional MOSFET wherein memory is stored in the form of charge trapped on floating-gate, affecting its threshold voltage. Two antagonistic quantum mechanical transfer processes, viz. hot e- injection and Fowler Nordheim tunneling, alter the trapped charge on FG.

Table 1. Main Characteristics of CCCII design at bias current, $I_{b}=800 \mu \mathrm{A}$ and biasing voltage $\pm 2 v$.

\begin{tabular}{lc}
\hline & AC Characteristic \\
\hline Current Gain $\alpha_{0}$ & 1.079 \\
$-3 \mathrm{db}$ bandwidth for $\alpha_{\mathrm{s}}$ & $4.7 \mathrm{GHz}$ \\
Voltage Gain $\beta_{0}$ & 0.559 \\
$-3 \mathrm{db}$ bandwidth for $\beta_{\mathrm{s}}$ & $5.24 \mathrm{GHz}$ \\
Intrinsic Resistance & $26.12 \mathrm{~K} \Omega$ \\
Output resistance & $843.56 \mathrm{M} \Omega$ \\
DC Characteristic & \\
Offset voltage at X & $35 \mathrm{mV}$ \\
Offset current at $Z$ & $350 \mathrm{pA}$ \\
Total Power dissipation & $1.509 \mathrm{~mW}$ \\
Temperature Stability & $0.0287 \mathrm{uA} /{ }^{\circ} \mathrm{C}$ \\
\hline
\end{tabular}

For simulation we have implemented a FGMOS model inspired from paper [16], in which the injection current and tunneling currents are modeled to program the threshold voltage of FGMOS. A schematic diagram of the FGMOS is represented in Figure 4(a) which depicts the indirect programming of FGMOS using a mos capacitor for tunneling and a programmer PMOS for injection, having common gate (the charge at this common gate can be inject/ remove thus termed as floating gate with the help of these two PMOSs). As these processes can occur during normal operation (indirect programmable FGMOS [17]), it leads additional attributes to the FGMOS transistors such as non volatile analog memory storage on floating-gate, locally computed bidirectional memory updates and memory modification during normal transistor operation. Hence the plot in Figure 4(b) illustrates the programmable threshold voltage of the FGMOS due to programmable charge at floating gate with the help of injection and tunneling mechanisms.

\subsubsection{Tunneling}


Charge is added to the floating gate by removing electron from it by means of Fowler-Nordheim tunneling across oxide capacitor (represented in simulation with mos capacitor). Thus, in the output characteristic of FGMOS, it shifts the curve (Figure 4(b)) to the right or in other words threshold voltage of the transistor increases.

\subsubsection{Injection}

Charge is removed from the floating-gate by adding electron on floating gate by impact-ionized hot electron injection from the channel to the floating gate across the thin gate oxide. Injection of electron is performed by programmer PMOS and increases charge at the common floating gate, which changes the characteristics of the FGPMOS used in respective circuit. Thus it shifts the curve (output characteristics of FGMOS in Figure 4(b)) to the left or in other words threshold voltage of the transistor decreases.

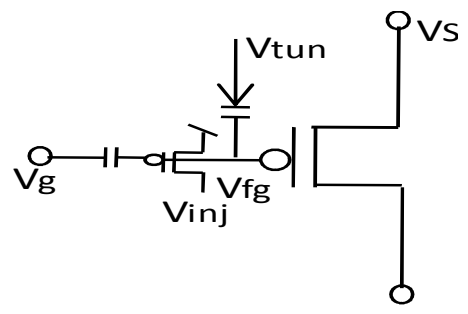

(a)

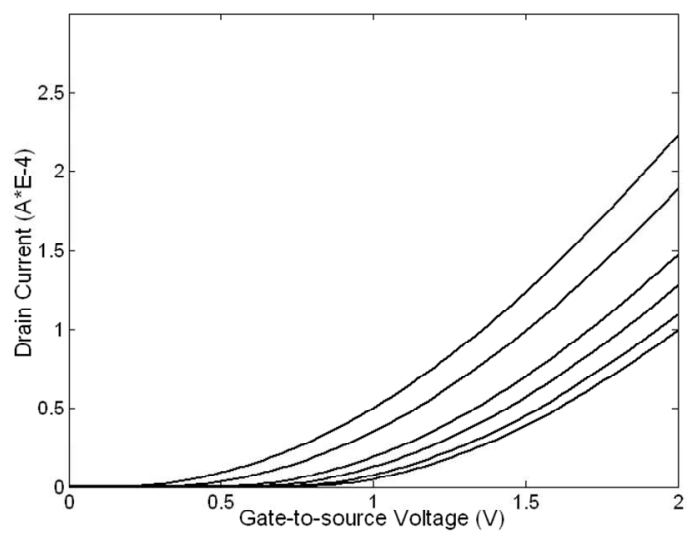

(b)

Figure 4. (a) Pictorial representation of a FGMOS with indirectly programmable floating gate using programmer MOS for injection (Vinj = Vsource( $(v d d)-V d(V i n j)$, Vinj is the pot difference between source and drain of programmer MOS) and MOS capacitor for tunneling(where $V_{\text {tun }}$ is tunneling junction potential) (b) Output Characteristics of a FGMOS.

\subsection{Sensitivity Analysis of Specifications}

\section{Current Gain}

The modified current conveyor circuit current gain and intrinsic impedance can be programmed after fabrication using a floating gate MOSFET respectively, along with offset corrections. Figure 5 represents circuit diagram of the modified CCCII where all MOSs are replaced by FGMOSs which in turn introduce programming ability of its design specifications. The current conveyor's current gain as expressed in equation (4) shows that it depends on various transistors. M12 and M13 make an identical current mirror thus the second term from equation (4) will become unity and current gain expression become:

$$
\begin{array}{r}
A_{i} \cong \frac{\left(s C_{g d 5}+g_{m 5}\right)\left(s C_{g d 2}-g_{m 2}\right)}{\left(s\left(C_{g d 5}+C_{g s 5}+C_{g s 4}\right)-g_{m 4}\right)\left(s\left(C_{g s 1}+C_{g s 2}+C_{g d 2}\right)+g_{m 1}\right)} \\
\frac{I_{b}}{i_{x}} \frac{s C_{g d 11}+g_{m 11}}{\left(s\left(C_{g d 11}+C_{g s 10}+C_{g 11}\right)-g_{m 10}\right.}
\end{array}
$$

In the above equation current gain depends on transconductance and after placing transconductance with respect to threshold voltages (relation shown in equation (2)), the gain shows dependence on various thresholds like, $\mathrm{V}_{\mathrm{t} 10}, \mathrm{~V}_{\mathrm{t} 11}$ and so on.

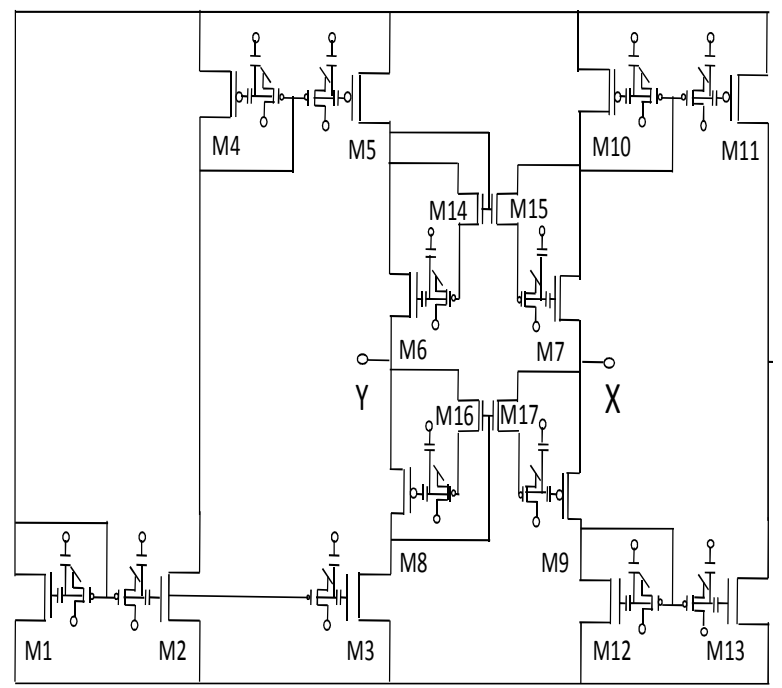

Figure 5. Modified CCCII circuit design based on charge difference between floating-gates, simulated using BSIM3 level 49 MOSFET models in T-Spice 0.35 $\mathrm{m}$ CMOS process. The floating-gate transistors are being represented symbolically showing indirect, non-volatile tunneling and injection technique.

Sensitivity of current gain with respect to threshold voltage of M10 can be evaluated by partial difference of equation (8), assuming rest all floating gate transistors with constant thresholds and hence is given by:

$$
S_{A i} /_{t h 10}=\frac{-k_{n 10} V_{t h 10}}{s\left(C_{g d 11}+C_{g s 10}+C_{g d 11}\right)+k_{n 10}\left(V_{g s 10}-V_{t h 10}\right)}(9)
$$

Neglecting the term

$$
\frac{s C_{g d 13}-g_{m 13}}{\left[s\left(C_{g d 13}+C_{g s 12}+C_{g s 13}\right)+g_{m 12}\right]},
$$

as numerator is very small than denominator, sensitivity of gain with respect to $V_{\text {th11, }}$ is given by:

$$
S_{A i} /_{t h 11}=\frac{-k_{11} V_{t h 11}}{s C_{g d 11}-k_{11}\left(V_{g s 11}-V_{t h 11}\right)}
$$

The equation (9) and (10) illustrate direct dependence of gain with thresholds of transistor M10 and M11. Figure 6(a) demonstrates the respective plots.

Intrinsic Impedance: Intrinsic impedance $\mathrm{R}_{\mathrm{x}}$ is given by 
equation (1) depends on bias current $\mathrm{I}_{\mathrm{b}}$ and transconductance of transistors M7 and M9. Substituting in terms of threshold voltage in equation (1), impedance can be expressed as:

$$
R_{x}=\frac{1}{\left(k_{7}\left(V_{g s 7}-V_{t h 7}\right)+k_{9}\left(V_{g s 9}-V_{t h 9}\right)\right.}
$$

Sensitivity of impedance with respect to threshold of M7, assuming $\mathrm{V}_{\text {th } 9}$ constant, is given by:

$$
\begin{gathered}
S_{R_{x} / V_{t h 7}}=\frac{-k_{7} V_{t h 7}}{\left[k_{7}\left(V_{g s 7}-V_{t h 7}\right)+c o n s t\right]}, \text { const } \\
=k_{9}\left(V_{g s 9}-V_{t h 9}\right)
\end{gathered}
$$

Similarly, sensitivity of intrinsic impedance with respect to $\mathrm{V}_{\text {th9 }}$ is given by:

$$
\begin{gathered}
S_{R_{x} / V_{t h 7}}=\frac{-k_{9} V_{t h 9}}{\left[k_{9}\left(V_{g s 9}-V_{t h 9}\right)+c o n s t\right]}, \text { const } \\
=k_{7}\left(V_{g s 7}-V_{t h 7}\right)
\end{gathered}
$$

The plot representing sensitivity analysis of intrinsic impedance with respect to $V_{t 7}$, as in expression (12), is shown in Figure 6 (b). The dominant floating gate transistor is M7 and hence is used for programming it after fabrication.

Output Offset Current at Z: Output offset current at Z, $\left(\mathrm{i}_{\mathrm{z}}(\mathrm{t})\right)$ when no input signal $\left(\mathrm{i}_{\mathrm{x}}(\mathrm{t})\right)$ is applied in the circuit, is expressed in equation (7) and in terms of thresholds, it is expressed as:

$$
\begin{gathered}
I_{o f f s e t}=\frac{k_{2}\left(V_{g s 2}-V_{t h 2}\right) k_{5}\left(V_{g s 5}-V_{t h 5}\right)}{k_{1}\left(V_{g s 1}-V_{t h 1}\right) k_{4}\left(V_{g s 4}-V_{t h 4}\right)}\left[\frac{k_{2}\left(V_{g s 13}-V_{t h 13}\right)}{k_{12}\left(V_{g s 12}-V_{t h 12}\right)}-\right. \\
\frac{k_{2}\left(V_{g s 11}-V_{t h 11}\right)}{k_{2}\left(V_{g s 10}-V_{t h 10}\right)}
\end{gathered}
$$

Sensitivity of offset current with respect to related thresholds, are expressed as:

$$
\begin{aligned}
& S_{I_{o f f s e t} / V_{t h 2}}=\frac{-V_{t h 2}}{\left(V_{g s 2}-V_{g s 2}\right)} \text { and } S_{I_{o f f s e t} / V_{t h 5}}=\frac{-V_{t h 5}}{\left(V_{g s 5}-V_{g s 5}\right)} \text {, } \\
& S_{I_{\text {offset }} / V_{t h 1}}=\frac{V_{t h 1}}{\left(V_{g s 1}-V_{g s 1}\right)} \text { and } S_{I_{\text {offset }}} / V_{t h 4} \\
& =\frac{V_{t h 4}}{\left(V_{g s 4}-V_{g s 4}\right)} \\
& \left.S_{I_{\text {offset }} / V_{\text {th } 10}}=\frac{-k_{10} V_{t h 10}}{\left(1 / C^{-1} / k_{10}\left(V_{g s 10}-V_{t h 10}\right)\right.}\right), C=k_{11}\left(V_{g s 11}-\right. \\
& V_{t h 11} \text {, assuming } \mathrm{g}_{\mathrm{m} 13}=\mathrm{g}_{\mathrm{m} 12} \\
& S_{I_{\text {offset }} / V_{\text {th } 11}}=\frac{k_{11} V_{t h 11}}{\left(c-k_{11}\left(V_{g s 11}-V_{t h 11}\right)\right)}, C=k_{10}\left(V_{g s 10}-\right. \\
& \left.V_{t h 10}\right) \text { assuming } \mathrm{g}_{\mathrm{m} 13}=\mathrm{g}_{\mathrm{m} 12} \\
& \begin{array}{c}
S_{I_{\text {offset }}} / V_{t h 12}=\frac{k_{12} V_{t h 12}}{\left(C-k_{12}\left(V_{g s 12}-V_{t h 12}\right)\right)}, C=k_{13}\left(V_{g s 13}-\right. \\
\left.V_{t h 13}\right) \text { assuming } g_{\mathrm{m} 10}=g_{\mathrm{m} 11}
\end{array} \\
& S_{I_{\text {offset }}} /_{V_{t h 13}}=\frac{-k_{13} V_{t h 13}}{\left(k_{13}\left(V_{g s 13}-V_{t h 13}\right)-C\right)}, C=k_{12}\left(V_{g s 12}-\right.
\end{aligned}
$$

$$
V_{t h 12} \text { ) assuming } \mathrm{g}_{\mathrm{m} 10}=\mathrm{g}_{\mathrm{m} 11}
$$

Hence offset current can be corrected using above mentioned floating gate transistors. However the dominant floating gate transistor to program offset current is M5. Therefore, gain and intrinsic impedance of modified CCCII circuit can be programmed and offset voltage and current can be corrected using a floating gate transistor respectively after fabrication.

Voltage Gain: Voltage gain between port X and Y is expressed by equation (3) while assuming transistors sizing and biasing condition constant for M6 and M7 second term of voltage gain can be neglected. Hence, voltage gain can be expressed as,

$$
A_{v}=\frac{\left[s\left(C_{g s 6}+C_{g s 7}\right)+k_{6}\left(V_{g s 6}-V_{t h 6}\right)+k_{7}\left(V_{g s 7}-V_{t h 7}\right)\right]}{\left[s C_{g d 2}-k_{2}\left(V_{g s 2}-V_{t h 2}\right)\right]}\left[\begin{array}{c}
{\left[s C_{g d 5}-k_{5}\left(V_{g s 5}-V_{t h 5}\right)\right] V_{b} / V_{x}} \\
{\left[s C_{g d 2}+k_{2}\left(V_{g s 2}-V_{t h 2}\right)\right]\left[s C_{g s 7}+k_{7}\left(V_{g s 7}-V_{t h 7}\right)\right]} \\
{\left[s C_{g d 5}+k_{5}\left(V_{g s 5}-V_{t h 5}\right)\right]}
\end{array}\right.
$$

Sensitivity of current gain with respect to threshold voltage of M2 is given by:

$$
S_{A v} /_{t h 2}=\frac{\left[1-k_{2}\left(V_{g s 2}-V_{t h 2}\right)^{2} \lambda_{n 2}\right] V_{t h 2}}{1 / k_{2}\left[1+k_{2}\left(V_{g s 2}-V_{t h 2}\right) \lambda_{n 2}\right]\left[1-k_{2}\left(V_{g s 2}-V_{t h 2}\right)\right]}(21)
$$

Similarly, sensitivity of voltage gain with respect to $V_{\text {th5 }}$ is

$$
S_{A v} /_{t h 5}=\frac{\left[k_{5}\left(V_{g s 5}-V_{t h 5}\right)^{2} \lambda_{n 5}-1\right] V_{t h 5}}{1 / k_{5}\left[1+k_{5}\left(V_{g s 5}-V_{t h 5}\right) \lambda_{n 5}\right]\left[1+k_{5}\left(V_{g s 5}-V_{t h 5}\right)\right]}
$$

Sensitivity of voltage gain with respect to $V_{\text {th }}$

$$
S_{A v / V_{t h 6}}=\frac{-k_{6} V_{t h 6}}{\left[s C_{g s 6}+k_{6}\left(V_{g s 6}-V_{t h 6}\right)+c\right.}, c=s C_{g s 7}+k_{7}\left(V_{g s 7}-\right.
$$

Similarly, with respect to $\mathrm{V}_{\text {th7 }}$ is expressed as:

$$
\begin{aligned}
& S_{A v / V_{t h 7}}= \\
& \frac{k_{7} V_{t h 7}}{\left[s C_{g s 7}+k_{7}\left(V_{g s 7}-V_{t h 7}\right)\right]\left[c o n s t+s C_{g s 7}+k_{7}\left(V_{g s 7}-V_{t h 7}\right)\right]^{\prime}}(24) \\
& \text { const }=s C_{g s 6}+k_{6}\left(V_{g s 6}-V_{t h 6}\right)
\end{aligned}
$$

The plot showing sensitivity analysis of voltage gain with respect to individual threshold voltages represented in Figure 6(c). Similarly output impedance is expressed as:

$$
\begin{gathered}
R_{o u t}= \\
1 \\
\frac{1}{\left[s\left(C_{g d 2}+C_{g d 3}+C_{g d 5}+C_{g d 7}+C_{g d 9}+C_{g d 11}+C_{g d 13}\right)+k_{2}\left(V_{g s 2}-V_{t h 2}\right)\right.} \\
+k_{2}\left(V_{g s 2}-V_{t h 2}\right)+k_{3}\left(V_{g s 3}-V_{t h 3}\right)+k_{5}\left(V_{g s 5}-V_{t h 5}\right)+k_{7}\left(V_{g s 7}-V_{t h 7}\right)+ \\
k_{9}\left(V_{g s 9}-V_{t h 9}\right)+k_{11}\left(V_{g s 11}-V_{t h 11}\right)+k_{13}\left(V_{g s 13}-V_{t h 13}\right)
\end{gathered}
$$

and sensitivity analysis of output resistance with respect to threshold of transistor M13 can be expressed as:

$$
S_{R_{\text {out }} / V_{\text {th } 13}}=\frac{-2 k_{13} \lambda_{n 13}\left(V_{g s 13}-V_{t h 13}\right)}{\left(k_{13}\left(V_{g s 13}-V_{t h 13}\right)^{2} \lambda_{n 2}+\text { const }\right)}(26)
$$


Simulation results illustrating such programming or sensitivity of respective characteristics while considering each transistor individually will be explained by plots and pro- gramming steps along with programming range are tabulated in Table 2.

Table 2. Programming steps to program specifications on-chip along with their range of programming.

\begin{tabular}{|c|c|c|}
\hline Characteristics of CCCII & Range & Programming Steps \\
\hline Current Gain $\left(\mathrm{A}_{\mathrm{i}}\right)$ & $\begin{array}{l}0.2-2.1 \text { (can program independently } \\
\text { with } 13 \text { bit resolution) }\end{array}$ & $\begin{array}{l}\text { Program with } V_{t 11} \text { while } R_{x}, A v \text { and Rout remain constant and offset cur- } \\
\text { rent reduced from } 261 \mathrm{pA} \text { to } 0.01 \mathrm{pA}\end{array}$ \\
\hline Intrinsic resistance $(\mathrm{Rx})$ & $\begin{array}{l}15 \mathrm{k}-51 \mathrm{k} \text { (can program independently } \\
\text { with } 13 \text { bit resolution) }\end{array}$ & $\begin{array}{l}\text { Program using } V_{t 7} \text { while } A_{i} \text { remain constant and offset current can be } \\
\text { compensated using } V_{t 9} \text {. }\end{array}$ \\
\hline Voltage Gain V(X)/V(Y) & $\begin{array}{l}1-1.20 \text { (cannot program it independently } \\
\text { with accuracy) }\end{array}$ & $\begin{array}{l}\text { Program using } V_{t 6} \text { while } R_{x} \text { need to be compensation using } V_{t 7} \text { and current } \\
\text { offset correction using } V_{t 9} \text {. }\end{array}$ \\
\hline $\begin{array}{l}\text { Output Impedance Rout } \\
\left(\text { ohm* } 10^{\wedge} 8\right)\end{array}$ & $\begin{array}{l}0.5 \mathrm{G}-20 \mathrm{G} \text { (can program independently } \\
\text { with } 13 \text { bit resolution) }\end{array}$ & $\begin{array}{l}\text { Program suing } V_{t 13} \text { independently while rest all the specifications remain } \\
\text { constant however offset current changes which can be compensated using } \\
V_{t 9}\end{array}$ \\
\hline $\begin{array}{l}\text { Offset current }\left(I_{z}\right) \\
\text { when } I_{x}=0(p A)\end{array}$ & $\begin{array}{l}239.40-282.34 \text { (can be compensated } \\
\text { independently) }\end{array}$ & $\begin{array}{l}\text { Compensate using } V_{t 9} \text { while rest all circuit specifications } R_{x}, A_{i}, A_{v} \text { and } \\
R_{\text {out }} \text { remain constant. }\end{array}$ \\
\hline
\end{tabular}

\subsection{Simulation Results Demonstrating Programming Steps, Used to Program Circuit Specifications}

The circuit diagram of Figure 4 representing modified CCCII design is simulated using BSIM3 level 49 MOSFET models using T-Spice $0.35 \mu \mathrm{m}$ CMOS process and the final circuit with minimum number of FGMOSs is verified using Cadence analog design tool, Virtuoso. Figure 6 (a) (b) and (c) represent programmable current gain, intrinsic impedance and voltage gain with respect to threshold of floating gate transistors M11/M10, M7 and M5/M6 respectively.

Figure 7 represent parametric analysis results of specifications with respect to respective threshold model parameter, Vtho. Figure 7(a) illustrates variation of Current gain and Intrinsic Impedance and Figure 7(b) illustrate Voltage gain and Output impedance with respect to programmable thresholds of M7, Vt7. Figure 7(c) illustrates variation of offset current at $\mathrm{Z}$ when no input current at $\mathrm{X}$ with respect to Vt7. It shows that while programming $\mathrm{Rx}$ with $\mathrm{Vt} 7$, there is very less change in offset current which can be compensated using programmable Vt9(as explained in figure 7(c)). Figure 7(d) demonstrates offset current programming with respect to $\mathrm{Vt} 9$ respectively, while circuit specifications current gain and intrinsic impedance remain constant. Similarly Figure 7(e) and (f) represents Current gain variation and Voltage gain and Output impedance with respect to threshold of M11, Vt11. It shows while programming current gain, intrinsic impedance $\mathrm{Rx}$, voltage gain $\mathrm{Ai}$ and output impedance Rout remain constant. However, offset current get reduced with programming Vt11, as shown in Figure 7(g). Figure $7(\mathrm{~h})$ illustrate the variation in output impedance Rout with programmable threshold of transistor M13 while other specifications (current gain, voltage gain and intrinsic impedance) remain constant. Similarly voltage gain Av can be programmed using floating gate transistor M6; however, while programming Av, intrinsic impedance Rx also varies. Thus, for independent programming of voltage gain, variation in intrinsic impedance needs to be compensated using floating gate transistor M7. Hence the modified programmable CCCII demonstrate independently programmable current gain using Vt11 and independently programmable intrinsic impedance i.e. programmable current control using Vt7, while offset current can be compensated using Vt9. In addition to, it can program voltage gain with programmable threshold Vt6 along with little compensation of other specifications ( $\mathrm{Rx}$ compensation using Vt7 and offset current compensation using Vt9) and independent programming of output impedance with programmable threshold Vt13. The Table 2 demonstrates the design data sheet illustrating the complete programming steps to program each specification 
independently and with 13-bit resolution accuracy. For particular sizing and biasing condition of the circuit it represent the programming range of each specification. It shows for particular sizing and biasing condition current gain can be programmed within 0.2 to 2.1 values with 13 -bit programming resolution using a FGMOS M11 while offset current reduces from $261 \mathrm{pA}$ to $0.01 \mathrm{pA}$. Intrinsic impedance can be programmed between the range from $15 \mathrm{~K}$ to $51 \mathrm{~K}$ using a FGMOS M7 while offset current can be compensated using FGMOS M9. However voltage gain can be programmed using M6 while intrinsic impedance need to be compensated using M7 and offset current using Vt9. In addition to output impedance is programmable within the range from $0.5 \mathrm{Gohm}$ to $20 \mathrm{Gohm}$ using a FGMOS M13, where all other specifications remain constant but offset current vary which can be compensated using M9. And offset current at $\mathrm{Z}$ when no input current is applied can be program independently using FGMOS M9. After sensitivity analysis using model parameter Vtho analysis, floating gate transistor simulation model (influenced from paper [17]) using external voltage sources Vtun, for tunneling and Vinj for injection is placed and simulation results are incorporated in Figure 7. It demonstrates current gain variation with variable tunneling voltage in Figure 8(a). The continuous variation in current gain with programmable injection of change at floating gate with the help of variable drain voltage (Vd_prog) of the programmer PMOS voltage is illustrated in Figure 8(b). Moreover Figure 8(c) demonstrates intrinsic resistance variation with programmable charge at floating gate with variable tunneling voltage and with programmable intrinsic resistance using injection is shown in Figure 8(d). Thus, the final modified circuit consists of three floating gate transistors is illustrated along with its fabrication layout in Figure 9.

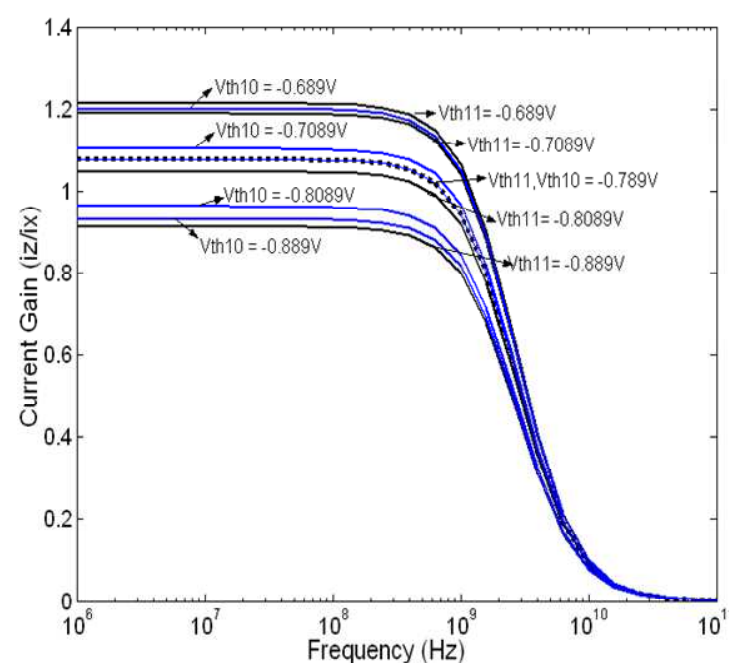

(a)

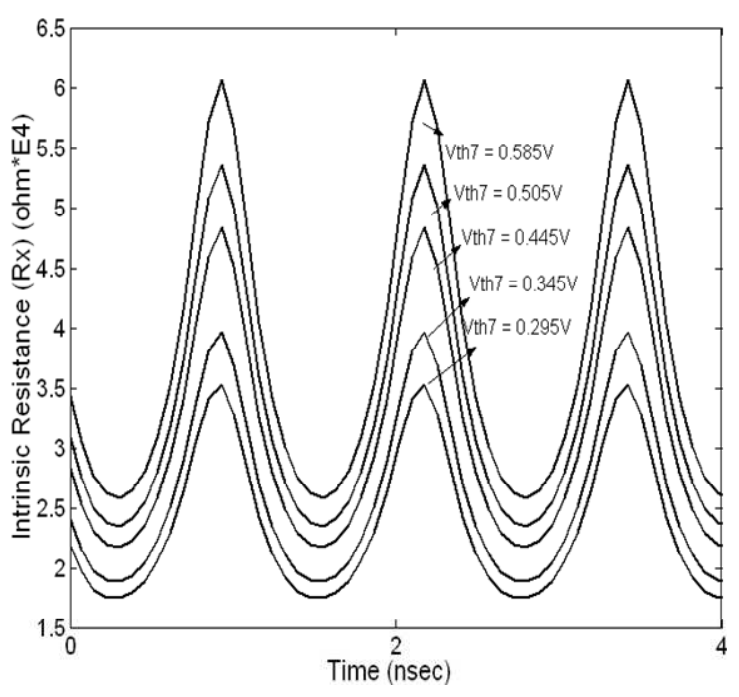

(b)

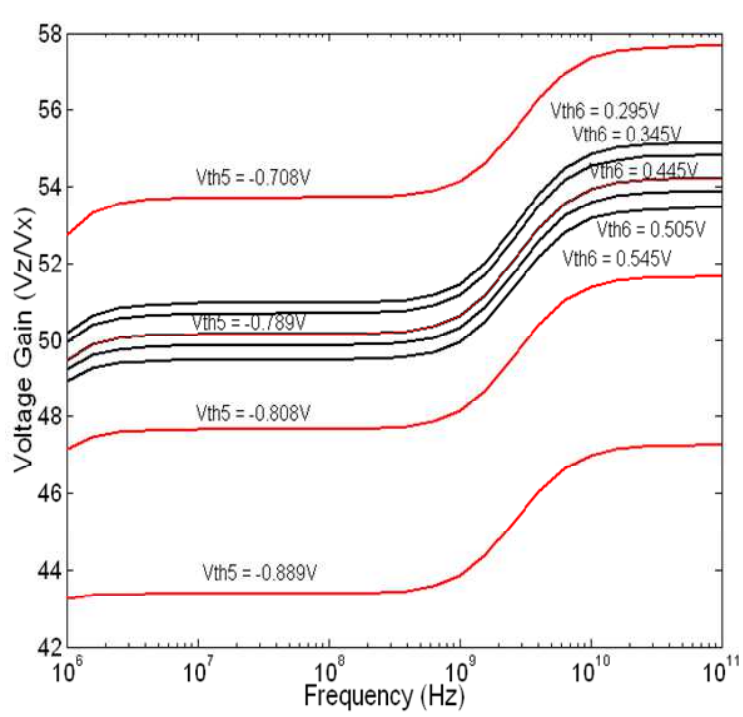

(c)

Figure 6. (a) Variation of Current gain with programmable thresholds of M10\&M11 floating-gate transistors (b) Variation of intrinsic impedance Rx with programmable threshold of M7 floating-gate transistors (c) Variation of Voltage gain Av with programmable threshold of M5 \&M6 floating-gate transistors.

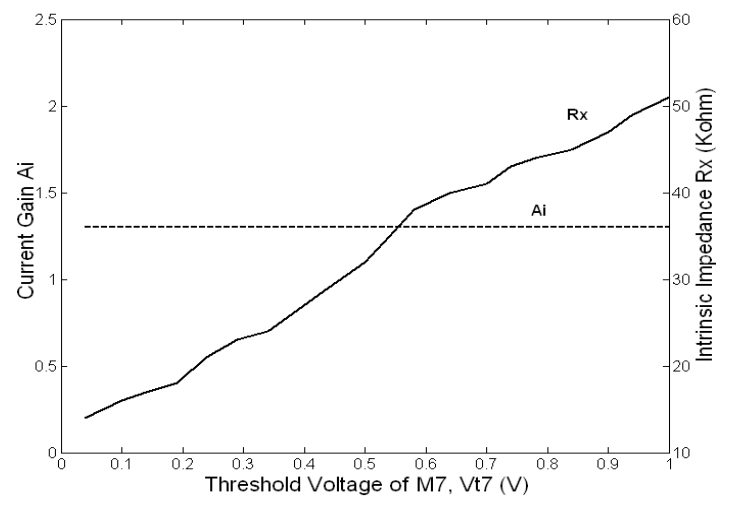

(a) 


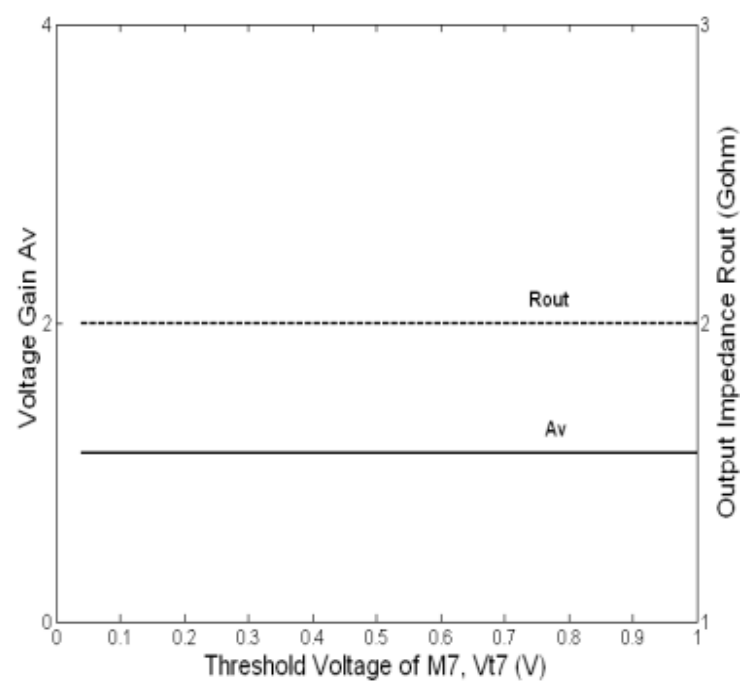

(b)

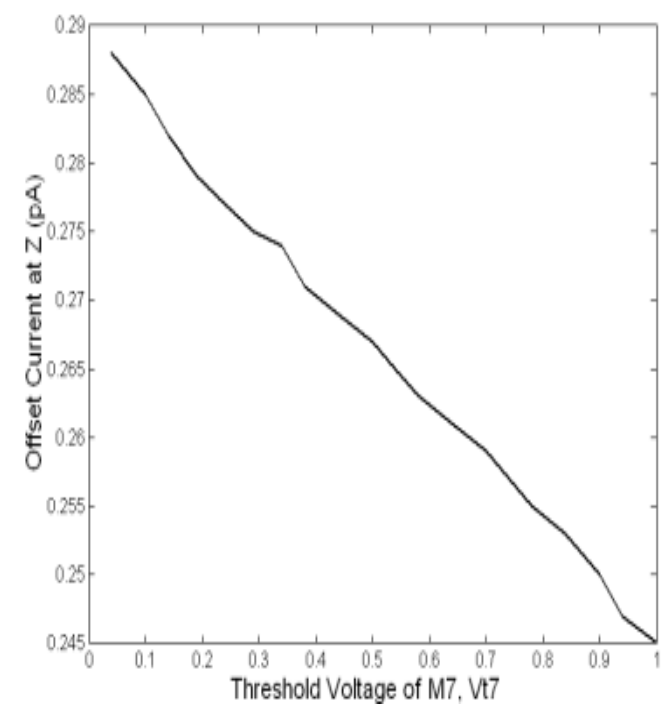

(c)

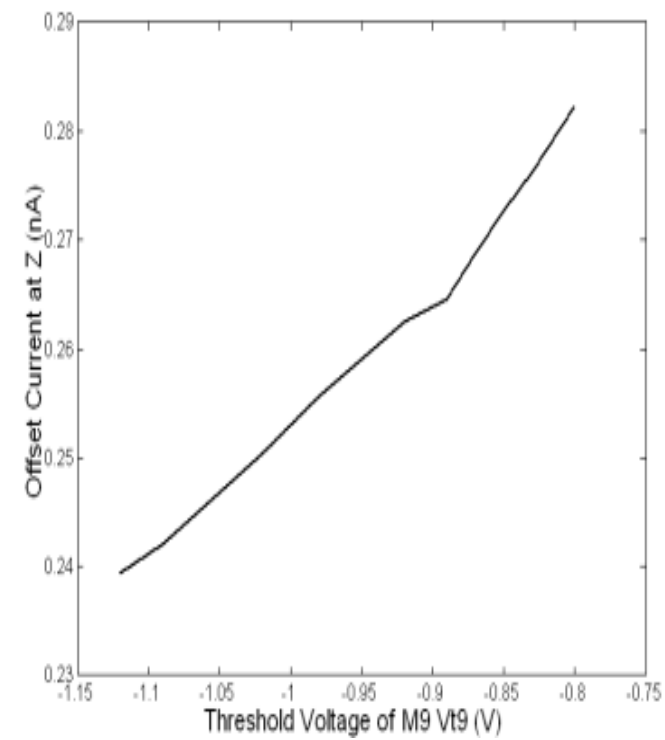

(d)

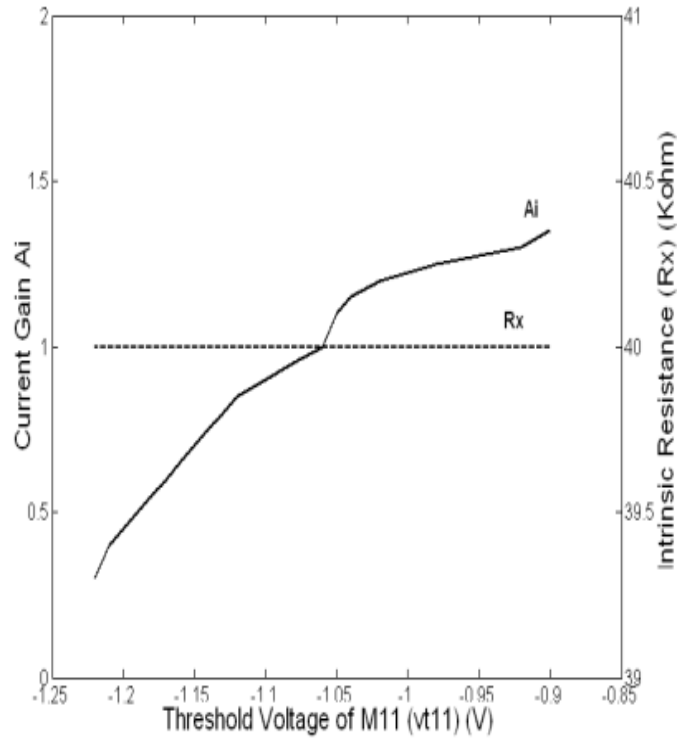

(e)

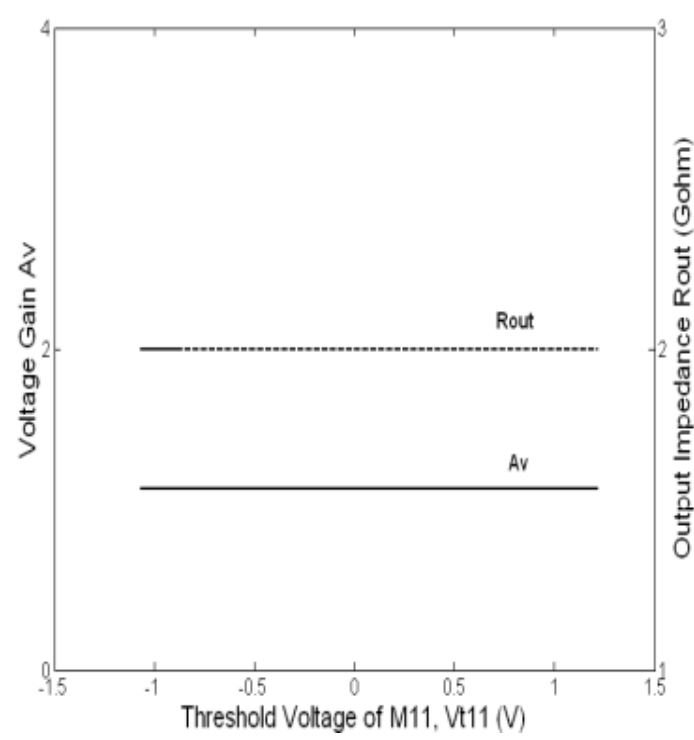

(f)

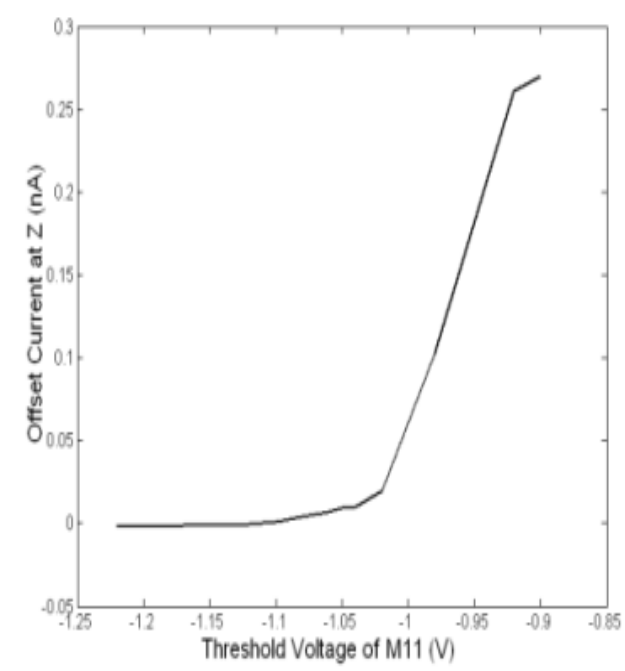

(g) 


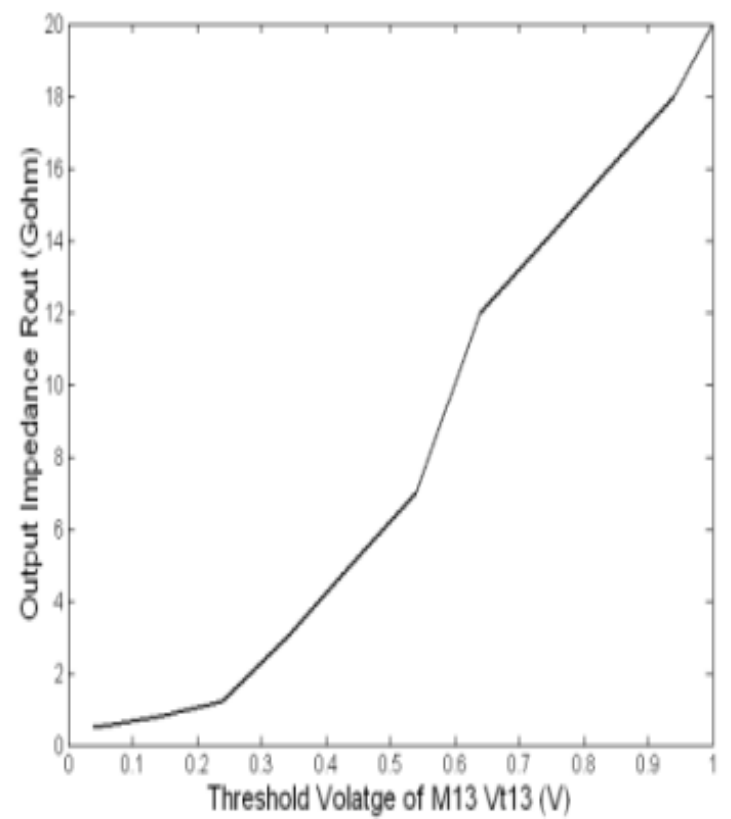

(h)

Figure 7. (a) Variation of Current gain and Intrinsic Impedance with programmable thresholds of $M 7, V t 7$ (b) Variation of Voltage gain and Output Impedance with programmable thresholds of $M 7, V t 7$ (c) Variation of offset current at $Z$ when no input current w.r.t Vt7 (shows while programming $R x$ with $V t 7$, very less change in offset which can be compensated with vt5) (d) Variation of offset current at $Z$ w.r.t Vt 5 (e) Variation of Current gain and Intrinsic Impedance with programmable thresholds of M11(f) Variation of Voltage gain and Output Impedance with programmable thresholds of M11, Vt11 (g) Variation of offset current at $Z$ when no input current at $X$ w.r.t Vt11(demonstrate that the offset current decreases while programming current gain or with increase in Vt11, offset decreases) (h) Variation of Output impedance Rout with programmable thresholds of M13 while rest all specifications current gain Ai, Intrinsic impedance Rx and voltage gain Av remain constant.

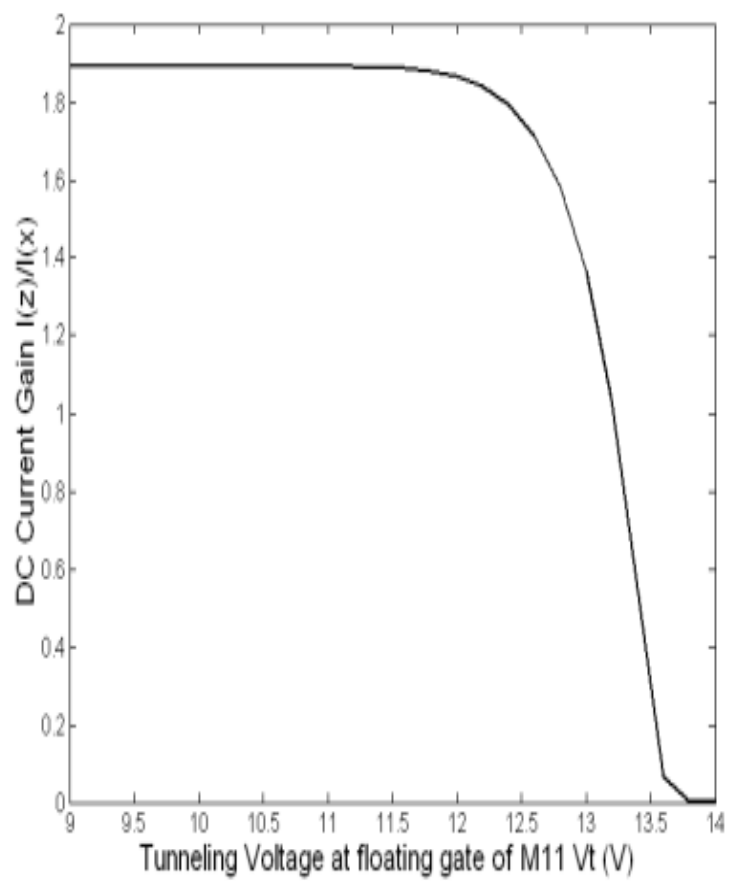

(a)

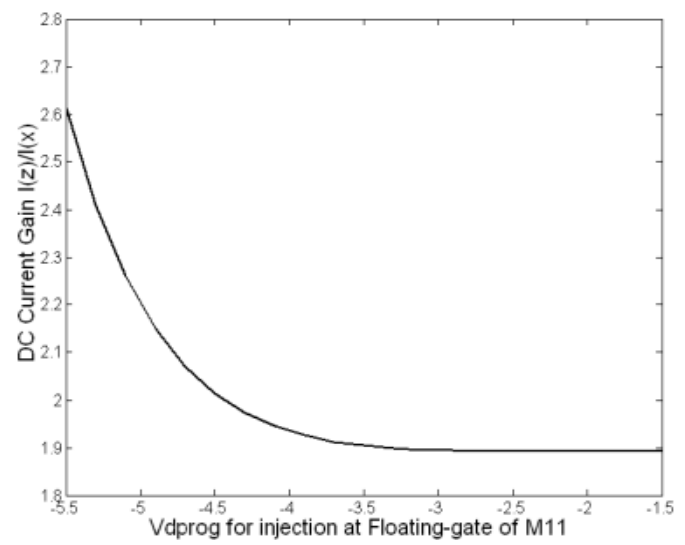

(b)

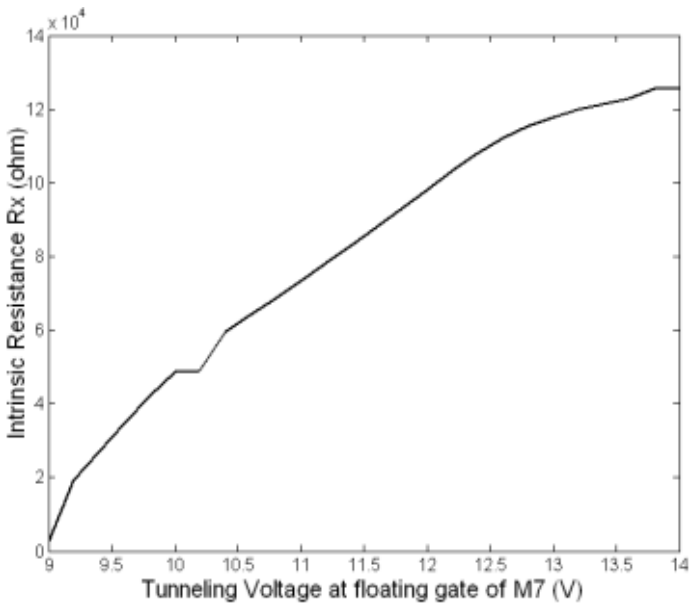

(c)

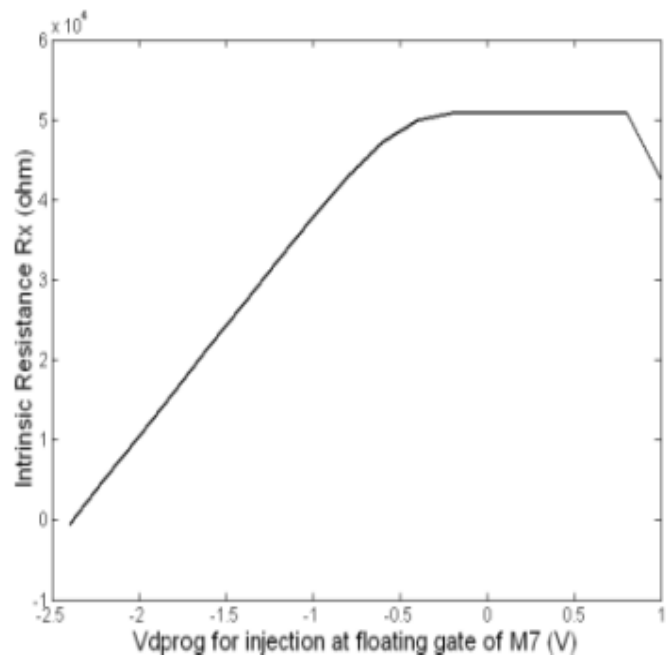

(d)

Figure 8. (a) Variation in dc Current Gain with tunneling voltage Vt, variation at the floating gate of floating gate transistor M11. (b) Variation in dc Current Gain with drain voltage of programmable FET, Vdprog, variation at common floating gate (however, injection voltage, Vinj= Vsprog-Vdprog), of floating gate transistor M11 (c) Variation in Intrinsic Impedance with tunneling voltage $V t$, at the floating gate of floating gate transistor M7 (d) Variation in Intrinsic Impedance with drain voltage of programmable FET, Vdprog, variation at common floating gate (however, injection voltage, Vinj= Vsprog-Vdprog), of floating gate transistor M11). 


\subsection{Final CCCII Circuit with Required Floating Gate Transistors and Its Programming Steps}

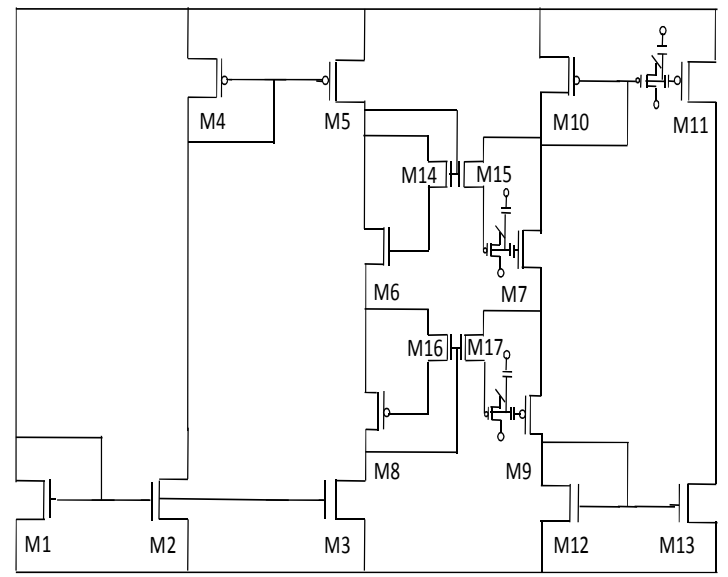

(a)

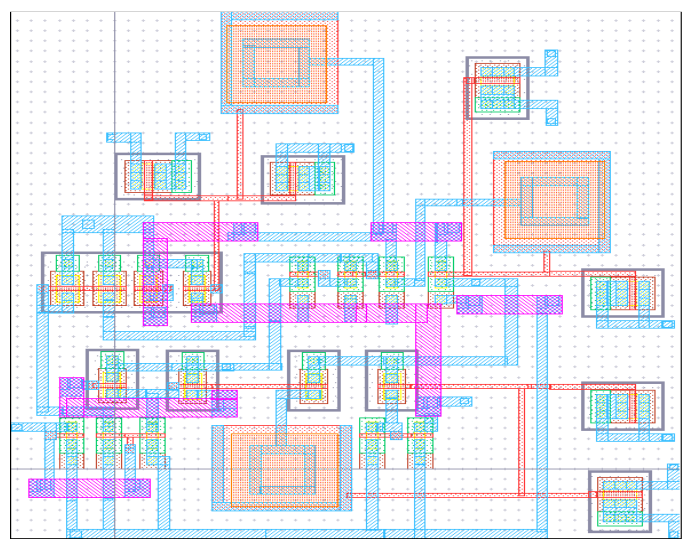

(b)

Figure 9. (a) Schematic of final modified Field Programmable CCCII developed using BSIM 3 level 49 models from the MOSIS fabrication services, in Virtuoso (Cadence analog designer tool) $0.35 \mu \mathrm{m}$ CMOS process using three FGMOSs. (b) Layout of final CCCII circuit in which gain and impedance can be programmed independently using a floating gate transistor (M11 and M7 respectively), which in turn can be programmed using two PMOSs (mos capacitor for tunneling and programmer PMOS for injection) at common floating gate, using external control voltages $V_{\text {tun }}$ and $V_{i n j}$, whereas, the charge at the floating gate can be stored at capacitor $(160 \mathrm{pF})$, placed between gate and floating gate of the floating gate transistor. The circuit occupies $65 \mu \mathrm{m} \times 54 \mu$ chip area.

The final modified programmable CCCII circuit which has independently accurate programmable current gain and current control along with offset current compensation is developed using only three floating gate transistors M11, M7 and M9 using Virtuoso, as shown in Figure 9(a). The modified circuit consists of FGMOSFET synapse model [24] which has input capacitor of value $160 \mathrm{fF}$ between gate and floating gate and two programmable pFETs with common floating gate, used for tunneling (using terminal vtun for example vtunforM11) and injection (using terminal vd_prog and vs_prog for example vdprogforM11/vsprogforM11)of charges at the floating gate. The design is also being developed for fabrication and the layout is demonstrated in Figure9 (b). The circuit occupies $65 \mu \mathrm{m} \times 54 \mu$ chip area. The layout too represents the modified CCCII circuit with three FGMOSFETs M11, M7 and M9. Each FGMOSFET consists of an input storing capacitor and two programming pFETs.

\section{Conclusion}

The proposed programmable CCCII design and final modified CCCII design simulation results illustrate that the circuit specifications, current gain, intrinsic impedance, voltage gain and output impedance can be programmed using floating gate transistor M11, M7, M6, M13 while offset current can be compensated using M9. The circuit specifications of modified second generation current conveyor are programmable after fabrication to desired value in the specific range using respective floating gate transistors as expressed in form of programming steps. And the specifications can be programmed with 13bit programming precision. As we have observed that specifications like current gain is programmable to very fine values, i.e. up to 13 bit precision and the same were claimed in paper [25] with experimental verification as well. Thus our proposed design can be programmed by field user continuously. Hence all three design objectives; variation in the specifications should be large and continuous, variation of each specification should be independent of the other and the operating point of the circuit should not alter too much during programming, i.e. offset current should not vary significantly, have been justified from our results. Therefore, proposed current conveyor design with fine programming of its design specifications after fabrication, occupy smaller chip area, low power consumption, show thermal stability and simpler procedure of on-chip programming. Thus it can be used to implement universal filter with fine-tunable central frequency and can be used as oscillator with fine tunable oscillating frequency. It can also be used to develop field programmable analog arrays where no additional circuitry is required for analog storing (non-volatile, indirect field-programming ability feature of FGMOS), to program its FGMOS analog voltages are used, hence for interconnections no extra circuitry will be required. Moreover the applicability of this design can be extended to remote electronic systems (like in electronic circuitry of spacecrafts) as well as in portable devices (as analog, compact hardware used).

\section{Acknowledgment}

I would like to thank Council of Scientific and Industrial Research, INDIA for funding my research work under Senior Research Fellowship.

\section{References}

[1] C. Toumazou, F.J.Lidgey, D. Laigh, "Analogue IC Design: The Current-mode approach", book published Peter Peregrinus Ltd., ISBN 086341297 1, 1990. 
[2] C. Toumazou, "Circuit and System Tutorials", book published by IEEE press, IEEE order no. PP5596, ISBN 0-7803-1170-1, 1996.

[3] C. A. Reis Filho, M. Santos, "A high-performance CMOS first-generation current conveyor", Proceedings of 1st IEEE International Caracas conference on Devices, Circuits and Systems, pp. 62-65, Dec, 1995.

[4] A. Sedra, K .Smith, "A second-generation Current Conveyor and its applications", IEEE Transac. On Circuit Theory, Vol.17, Issue.1, pp.132-134, Feb, 1970.

[5] O.Oliaci, "Compound current conveyor (CCII+ \& CCII-)", Electronic letter, Vol.33, Issue.4, pp.253-254, 1997.

[6] I. A. Awad, "Inverting second generation current conveyors: the missing building blocks, CMOS realizations and applications", International Journal of Electronics, Vol. 86, Issue. 4, pp. 413-432, 1999.

[7] S.M.A.Shahrani, M.A.A.Absi, "New Realizations of CMOS Current Controlled Conveyor with variable Current Gain and Negative Input Resistance”, IEEE 46th Midwest Symposium on Circuit and System proceedings, vol.1, pp. 43-46, 2005.

[8] W. Chaunhua, S. Zhixing, L. Haiguang, "New CMOS Current-controlled second generation Current Conveyors", IEEE conference on Circuit and System for Communication proceeding, ICCSC, pp. 333-337, 2008.

[9] N. Hassen, T Ettaghzouti, K. Besbes, "High-performance Second generation controlled current conveyor CCCII and High Frequency Applications", World Academy of Science, Engineering and Technology 60, pp. 1361-1370, 2011.

[10] H. Z. Abouda, A. Fabre, "A New Balanced CMOS Controlled Integrator for Ultra High Frequency Applications", Analog Integrated Circuit and Signal Processing, no. 47, pp. $13-22,2006$.

[11] Z. Abbas, G Scotti, M. Olivieri, "Current Controlled Current Conveyor (CCCII) and Application using 65nm CMOS Technology, World Academy of Science, Engineering and Technology, Paris, France, July 27-29, 2011.

[12] C.M.Chang, T.H.Huang, S.H.Tu, C.L.Hou, J.W.Horng, "Universal Active Current Filter Using Single Second-generation Current Controlled Conveyor", Electronic letter, Vol. 27, pp. 1614-1617, 1991.

[13] M. Y. Yasin, B. Gopal, "High Frequency Oscillator Design using a single $45 \mathrm{~nm}$ CMOS Current controlled current conveyor (CCCII+) with Minimum Passive Components", Scientific Research Circuit and System, Vol.2, pp. 53-59, 2011.

[14] S. Mahmoud, "Low power Low-Pass Filter with Programmable Cutoff Frequency Based On a tunable Unity Gain Frequency Operational Amplifier", Journal of Circuits, Systems and Computers, Vol.19, pp.1-13, 2010.

[15] S. Mahmoud, "Digitally Controlled CMOS Balanced Output Transconductor and Application to Variable Gain Amplifier and Gm-C Filter on Field Programmable Analog Array", Journal of Circuits, Systems and Computers, Vol.14, pp. 667 $-684,2005$.
[16] S. Mahmoud, M. Hashiesh, A. Soliman, "Low-Voltage Digitally Controlled Fully Differential Current Conveyor", IEEE Trans. on Circuits and Systems I, Vol. 52, pp.2055-2064, 2005.

[17] J. Becker, F. Henrici, S. Trendelenburg, M. Ortmanns, Y. Manoli, " A Field-Programmable Analog Array of 55 Digitally Tunable OTAs in a Hexagonal Lattice", IEEE Journal of Solid-State Circuits, Vol. 43, pp. 2759-2768, 2008.

[18] S. Mahmoud, M. Hashiesh, A. Soliman, "Low-Voltage Digitally Controlled Fully Differential Current Conveyor", IEEE Trans. on Circuits and Systems I Vol.52, pp. 2055-2064, 2005.

[19] T. Hassan, S. Mahmoud, "Fully Programmable Universal Filter with Independent Gain-oo-Q Control Based On New Digitally Programmable CMOS CCII. Journal of Circuits, Systems and Computers, Vol.18, pp. 875-897, 2009.

[20] I.A.Khan, A.M.Nahhas, "Current mode programmable Analog modules using low voltage digitally controlled CMOS CCII", International journal of Computer Applications",Vol. 48, No.4, pp. 997-888, June 2012.

[21] P. Hasler and J. Dugger, "An analog floating-gate node for supervised learning," IEEE Trans. Circuits Syst. I, Reg. Papers, Vol. 52, no. 5, pp. 834-845, 2005.

[22] P. Brady and P. Hasler, "Offset compensation in flash ADCs using floating-gate circuits," in IEEE Proceedings of the International Symposium on Circuits and Systems, pp. 6154-6157, 2005.

[23] D. W. Graham, E. Farquhar, B. Degnan, C. Gordon, and P. Hasler, "Indirect programming of floating-gate transistors," in Proceedings of the IEEE International Symposium on Circuits and Systems, May, pp. 2172 - 2175, 2005.

[24] K. Rahimi, C. Diorio, C. Hernandez, M.D.Brockhausen, "A Simulation model for floating gate MOS synapse transistors," IEEE International Symposium on Circuit and Systems, Vol. 2, pp. 532-535, 2002.

[25] Y.L.Wong, M.H Cohen, P.A.Abshire,” A $1.2 \mathrm{GHz}$ adaptive floating gate comparator with 13-bit resolution", IEEE proceeding of conference ISCAS, Vol.6, pp. 6146-49, 2005.

[26] G.Kapur, S.Mittal, C.M.Markan, V.P.Pyara, "To develop a design methodology for an Analog Field Programmable CMOS Current Conveyor", proceedings of IEEE student conference SCES 2012, MNNIT, Allahabad, pp. 1-6, 16th -18th March, 2012.

[27] G. Kapur, S. Mittal, C.M.Markan, V.P.Pyara, “A Unique Design Methodology to generate reconfigurable Analog ICs with simplified Design Cycle." Proceeding of an International Workshop for Unique Chips and systems, in conjunction with IEEE HPCA-2012, New Orleans, Louisiana, USA, pp. 28-33, 25-29th Feb 2012.

[28] G.Kapur, C.M.Markan, "Design Methodology for Analog Circuit Designs using Proposed Field Programmable Basic Analog Building Blocks", proceedings of IEEE (CAS) conference Field Programmable Technology, FPT'11, IIT Delhi, 12th to 14th Dec, 2011. 